\title{
THE DESIGN AND ANALYSIS OF A BRAKE DISC OF THE TWO WHEELER
}

\author{
G.VINAY KUMAR ${ }^{1} \&$ Dr. P. HARI SANKAR ${ }^{2}$ \\ ${ }^{1}$ Student, Department of Mechanical Engineering, G.Pulla Reddy Engineering College, \\ Kurnool, Andhra Pradesh, India \\ ${ }^{2}$ Associate Professor, Department of Mechanical Engineering, G.Pulla Reddy Engineering College,
}

Kurnool, Andhra Pradesh, India

\begin{abstract}
When we talk about vehicle performance one must think its capacity and engine efficiency. Along with this braking system is also one of the major essential system in a vehicle to the application of stop or slow. So in a brake system one of the important parts (i.e., brake disc) which faces different types of forces and thermal stresses in it during braking phase. So, a brake disc should have capability to bear all that force while in any working conditions. For this the material and the design should be the major criteria taken into account. We took Bajaj pulsar $220 \mathrm{~F}$ model as an example for parameters. In this work 3 different disc designs were taken with 3 different materials such as Grey cast iron grade 250 (GCI), Stainless Steel (SS)and Titanium Alloy (TA). With all these, structural analysis and thermal analysis is done with the help of ANSYS 14.5. From the two analysis we got the results and we concluded that the disc 1 with stainless steel material possessing best outputs in terms of static structural and the same disc with grey cast iron possessed better results in terms of transient thermal among the 3 disc design models. So, the disc 1 is concluded as optimum disc design and suitable for automobile braking applications.
\end{abstract}

KEYWORDS: Braking System, Heat Generation, Performance, Tangential Force \& Analysis etc.

Received: May 11, 2018; Accepted: May 31, 2019; Published: Jul 03, 2019; Paper Id.: IJMPERDAUG201950

\section{INTRODUCTION}

When it comes to design a disc rotor, design plays a crucial role to withstand the forces exerted by brake pads, for this the author has designed a different models with different patterns and did the three analysis finally they met optimized disc [1].Settling of cracks near to the holes will be effect on performance and according to the authors, life span of a brake disc strictly depends on geometry like holes position, type of spokes and its shapes. So that geometry and placing of patterns is important while designing a disc rotor and it should possess better results [2].Sometimes there may be disturbing noises arising from the braking system and as well as creating vibrations. From the authors it is stated that the squeal noise and vibration mode patterns depends on the material properties. Material selection plays a very important role in the elimination of squeal noises and unwanted vibrations [3].In this paper the author has carried out a study on thermal effects on a disc and pad assembly. By this they done analysis on disc pad model to know the temperature while in contact [4].In a designing phase disc pattern also plays a major part which is more influential on output. In this the author modelled different fin type's disc and fin number has been included. Though in their analysis the number of fins which are influenced in results. In their study the forward curved fins possess good results with optimal fin numbers and also influenced on Reynolds as well as Nusselt number which was improved by the disc designs [5] when it comes to contacting of brake pads and 
disc. For this there is a pressure distribution will be occurring so the authors has taken more number of modifications. Finally they met there requirement with optimal modification. By their results the authors was stated that the right connection between piston ring and back plate in the axial direction will give better pressure distribution so that optimal contact will be established [6].In a braking phase the different contact behavior will occur between the components like pad and disc rotor. The author has carried out a study on thermo-mechanical dry contact behavior. In their study they said that every braking application there will be heat generation occurs. For that in their analysis they stated that the cast iron is the best suitable material in terms of heat generation. So that the cast iron has better thermal properties and it will possesses better thermal results while in braking phase [7].Ventilation and non-ventilation disc design possess different outputs so the author has taken a disc designs with vanes. They had taken 3 different vanes disc designs and full solid disc. From the results, the authors stated that the curved vanes disc produced better results in terms of temperature generation over the other types. So they concluded with the forward fins disc design as optimal disc [8].

\section{INPUT PARAMETERS}

- Outer diameter of a disc $=260 \mathrm{~mm}$.

- $\quad$ Disc material = grey cast iron ASTM grade 250(GCI), stainless-steel (SS) and titanium alloy (TA).

- Thickness of a disc $=5 \mathrm{~mm}$.

- $\quad$ Pad brake area $=2212 \mathrm{~mm}^{2}$.

- Permissible temperature $=260{ }^{\circ} \mathrm{C}$.

- Maximum pressure $=1 \mathrm{Mpa}$.

- Coefficient of friction $=0.3$ to 0.5 .

- Mass of the vehicle $=155 \mathrm{Kg}$ (model-Bajaj pulsar 220F).

Table 1: Properties of Materials

\begin{tabular}{|l|l|l|l|}
\hline Properties & GCI & SS & TA \\
\hline Young's modulus, Gpa & 180 & 200 & 96 \\
\hline Poisson ratio & 0.29 & 0.3 & 0.36 \\
\hline Density, $\mathrm{kg} / \mathrm{m}^{3}$ & 7500 & 7850 & 4620 \\
\hline Ultimate tensile strength (UTS), Mpa & 250 & 460 & 1 \\
\hline Yield tensile strength, Mpa & 170 & 250 & 0.9 \\
\hline Shear modulus, Gpa & 69 & 166 & 35 \\
\hline Bulk modulus, Gpa & 149 & 79 & 114 \\
\hline Thermal conductivity,W/m-K & 46 & 60.5 & 21.9 \\
\hline Thermal expansion, $\mu \mathrm{m} / \mathrm{m}-\mathrm{K}$ & 11 & 12 & 9.4 \\
\hline Specific heat capacity, J/kg-K & 490 & 434 & 522 \\
\hline
\end{tabular}

Table 2: Properties of Air and Pad

\begin{tabular}{|l|l|l|}
\hline Properties & Air & Pad \\
\hline Thermal conductivity, $\left(\mathrm{W} / \mathrm{m}^{0} \mathrm{C}\right)$ & 0.026 & 5 \\
\hline Thermal expansion, $\left(\mu \mathrm{m} / \mathrm{m}^{0} \mathrm{~K}\right)$ & $3.34 \times 10^{-3}$ & - \\
\hline Specific heat capacity, $\left.\mathrm{c} / \mathrm{Jg} \mathrm{kg}^{0} \mathrm{~K}\right)$ & 1005 & 1000 \\
\hline Absolute viscosity, $\left(\mathrm{m}^{2} / \mathrm{s}\right)$ & $1.9 \times 10^{-5}$ & - \\
\hline Density, $\left(\mathrm{kg} / \mathrm{m}^{3}\right)$ & 1.17 & 1400 \\
\hline Poisson ratio & - & 0.25 \\
\hline Coefficient of friction, $\mu$ & - & 0.2 \\
\hline Young's modulus, $(\mathrm{Gpa})$ & - & 1 \\
\hline
\end{tabular}




\section{CALCULATIONS}

Tangential force between pad and rotor, FTRI $=\mu$.FRI

Where,FRI $=\frac{P_{\max }}{2} \times$ pad brake area

Taken as, $\mu=$ coefficient of friction $=0.4$

Then, FTRI $=(0.4)\left(0.5 \times 10^{-6} \mathrm{~N} / \mathrm{m}^{2}\right)\left(2212 \times 10^{6} \mathrm{~m}^{2}\right)=442.4 \mathrm{~N}$

Both inner and outer tangential force are equal.

Total tangential force,FT $=$ FTRI + FTRO $=442.4+442.4=884.8 \mathrm{~N}$

Braking torque, $\mathrm{T}_{\mathrm{B}}=\mathrm{FT} \times \mathrm{R}$ (where $\mathrm{R}$ is the radius of rotor disc)

$$
=884.8 \times 130 \times 10^{-3}=115.024 \mathrm{~N}-\mathrm{m} .
$$

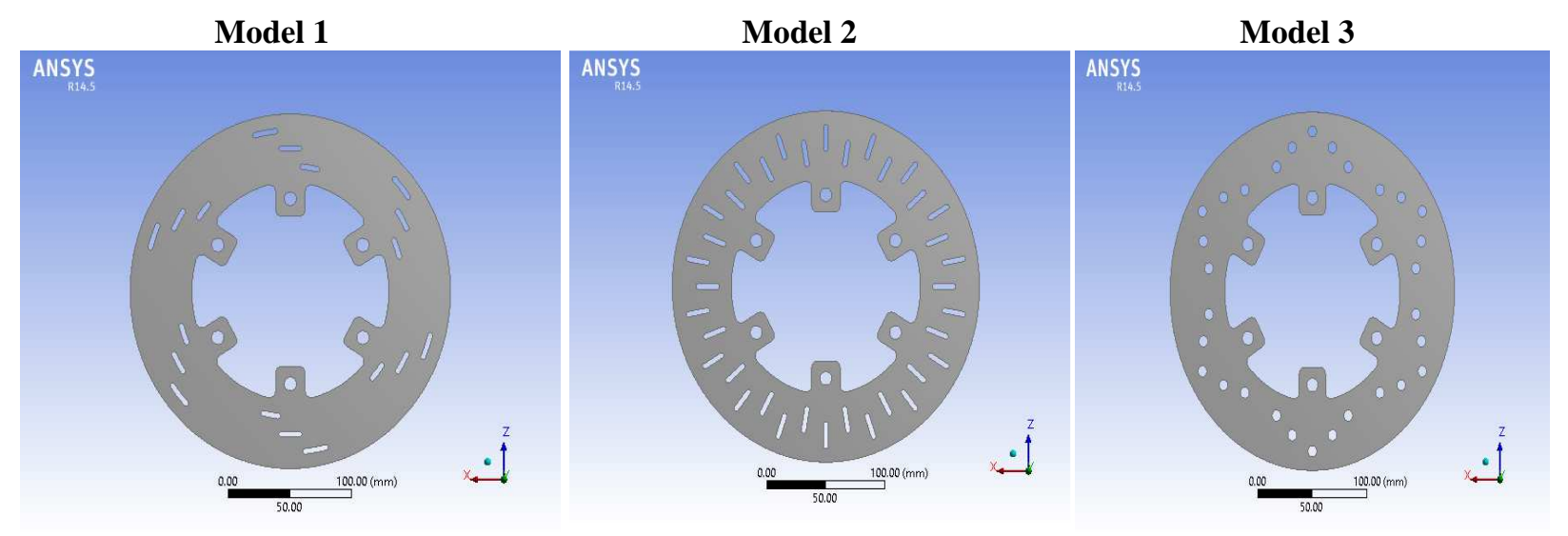

Figure 1: Following are the 3 New Different Disc Design Models

\section{DESIGN DESCRIPTION}

Above designs are unique and different to each other. In all these design models, the physical measurements that we took (common outer and inner diameters for all disc models) as $\mathrm{D}=260 \mathrm{~mm}$ and $\mathrm{d}=160 \mathrm{~mm}$. and thickness of the disc is $5 \mathrm{~mm}$. The holder hole diameter for every disc model is $d_{h}=10 \mathrm{~mm}$. And when it comes to the cut patterns we taken as holes with different spacing, slots with different angles along with different shapes of slots. All these criteria we have taken, will give better ventilation in the sense of heat generation and dissipation and also structurally withstanding the stresses while in the braking action.

\section{EXPERIMENTAL WORK}

\section{Static Structural Analysis}

It is one of the analysis in the analysis systems in workbench. In this we could come to know the deformation and von-mises stresses and also other structural results. Mainly in this project we focused on deformation with respect to stresses after applying loads, supports and moments as boundary conditions to determine the analysis results. Boundary conditions we were applied is tangential forces, fixed support at the holder holes i.e., 6 holes and the moment when the brake is applied there will be some torque generated in the disc. By all these conditions the analysis is done on three 
different disc models.



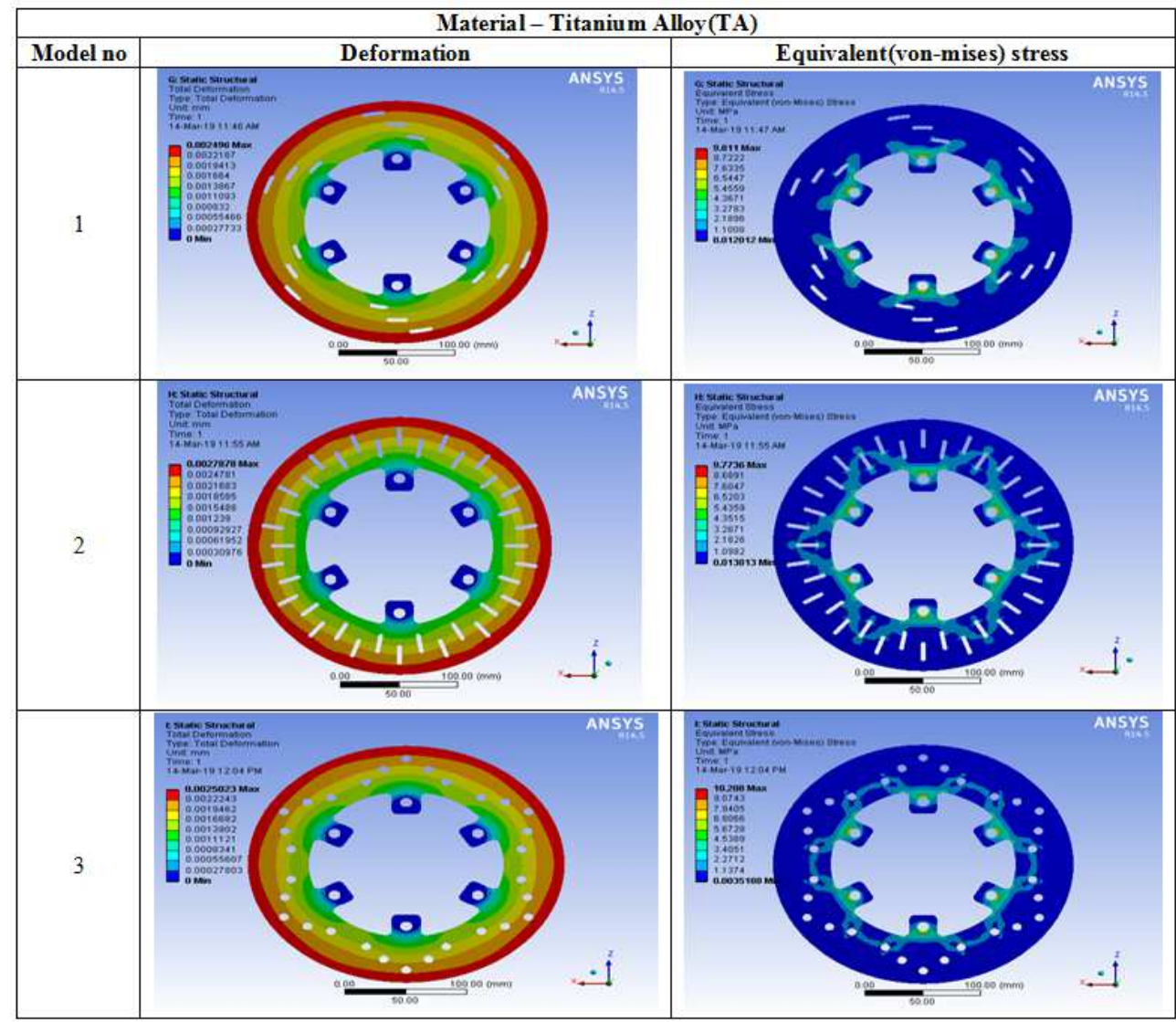

Figure 2: Structural Results of Disc with Grey Cast Iron

Table 3: Static Structural Results

\begin{tabular}{|c|c|c|}
\hline \multicolumn{3}{|c|}{ Material - Grey Cast Iron Grade 250(GCI) } \\
\hline & Total Deformation In mm & Equivalent(von-mises) stress in Mpa \\
\hline Disc 1 & 0.0012957 & 9.9784 \\
\hline Disc 2 & 0.0014511 & 9.9044 \\
\hline Disc 3 & 0.0013005 & 10.267 \\
\hline \multicolumn{3}{|c|}{ Material - Stainless Steel(SS) } \\
\hline & Total Deformation In mm & Equivalent(von-mises) stress in Mpa \\
\hline Disc 1 & 0.0011708 & 9.9547 \\
\hline Disc 2 & 0.0013107 & 9.8864 \\
\hline Disc 3 & 0.0011749 & 10.26 \\
\hline \multicolumn{3}{|c|}{ Material - Titanium Alloy(TA) } \\
\hline & Total Deformation In mm & Equivalent(von-mises) stress in Mpa \\
\hline Disc 1 & 0.002496 & 9.811 \\
\hline Disc 2 & 0.0027878 & 9.7736 \\
\hline Disc 3 & 0.0025023 & 10.208 \\
\hline
\end{tabular}

\section{TRANSIENT THERMAL ANALYSIS}

In this analysis, time is required to do thermal solution. Boundary conditions and the time setup is needed as input parameters to each disc model for the three materials. Before this we calculated the heat flux and convective heat transfer coefficient(for forced convection) using below equation. Heat is generated in a disc in the process of braking. When the vehicle is at a speed of $100 \mathrm{~km} / \mathrm{hr}$. In that time of action when brake is applied, the heat is generated in a disc by the action of pad contact before the vehicle stops. Assuming that, the Heat is generated in a disc is directly proportional to kinetic energy of the vehicle. 
Heat flux equation, $\mathrm{q}=\frac{\frac{1}{2} m v^{2}}{\frac{\text { area }}{\text { time }}}$

Where, $\mathrm{m}=$ mass of the vehicle, $[(\mathrm{m}=155 \mathrm{~kg})$ Bajaj pulsar $220 \mathrm{~F}], \mathrm{v}=$ velocity of the vehicle $(\mathrm{v}=100 \mathrm{~km} / \mathrm{hr}$. or 27.77 $\mathrm{m} / \mathrm{s})$, Stopping distance of the vehicle $=48.04 \mathrm{mts}$,

From the equation of motion, Time taken to stop the vehicle is $3.46 \mathrm{sec}$.

Intensity of heat flux is different for each model because the pad contacted area on a disc is different for different pattern models.

Table 4

\begin{tabular}{|l|c|c|}
\hline S No. & Area in $\mathbf{~}^{\mathbf{2}}$ & Heat flux in $\mathbf{~} / \mathbf{m}^{\mathbf{2}} \mathbf{C}$ \\
\hline Disc 1 & 0.026371 & 655014.27 \\
\hline Disc 2 & 0.024874 & 694435.15 \\
\hline Disc 3 & 0.026122 & 661257.94 \\
\hline
\end{tabular}

Convective heat transfer is calculated from $\mathrm{Nu}, \mathrm{Rn}$ and $\mathrm{Pd}$ number equation. i.e., $\mathrm{h}=110.241 \mathrm{~W} / \mathrm{m}^{20} \mathrm{C}$.

Boundary Conditions,

- Heat flux,

- $\quad$ Convective Film coefficient and

- $\quad$ Radiation (ambient temperature).

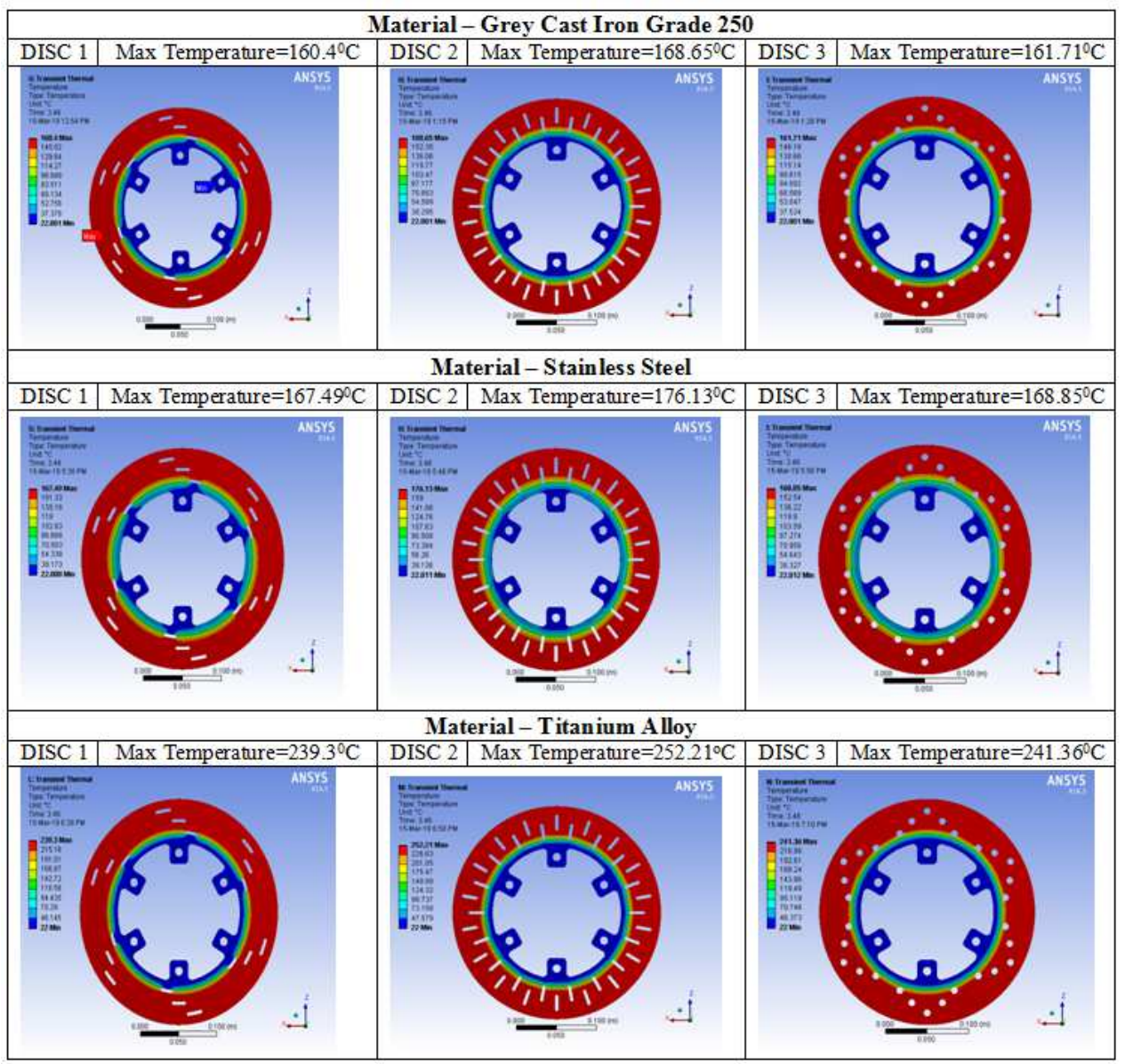

Figure 3: Results of Transient Thermal 
Table 5: Thermal Results of Three Materials

\begin{tabular}{|l|l|l|l|}
\hline \multirow{2}{*}{ Models no. } & \multicolumn{3}{|c|}{ Materials } \\
\cline { 2 - 4 } & GCI & \multicolumn{1}{|c|}{ SS } & TA \\
\cline { 2 - 4 } & \multicolumn{3}{|c|}{ Temperature in ${ }^{\mathbf{0}} \mathbf{C}$} \\
\hline 1 & 160.4 & 167.49 & 239.3 \\
\hline 2 & 168.65 & 176.13 & 252.21 \\
\hline 3 & 161.71 & 168.85 & 241.36 \\
\hline
\end{tabular}

From the above results it is clearly observed that the disc 1 result among three materials obtained less temperatures over the other 4 disc models. Titanium material got higher temperature values so it has poor thermal properties compare to grey cast iron and stainless steel. Grey cast iron material got less temperature over the other two materials. So it is clear that the grey cast iron has better thermal properties and possessing less temperatures. Temperature and heat flux values are depends on disc geometry and thermal properties. So the design of a disc should be optimum and the disc materials must have better thermal properties.

\section{RESULTS}

In this fem results, the disc 1 model with grey cast iron material produced better thermal results than other two. The lowest temperature obtained as $160.4{ }^{\circ} \mathrm{C}$ which is appreciably low compared to other disc models. Even though disc 3 also got low temperature as $161.71{ }^{\circ} \mathrm{C}$ but here we have taken less temperature values. In structural analysis results disc 1 and disc 3 models obtained approximate values but we considered less value. For this disc 1 with stainless steel has obtained $0.00117 \mathrm{~mm}$ deformation and 9.954Mpa equivalent (von mises) stress. So the stainless steel with disc model have produced better outputs.

\section{CONCLUSIONS}

By these analysis we concluded with the result that the stainless steel (SS) has better structural characteristics than grey cast iron (GCI). In thermal analysis, grey cast iron material produced optimum temperature than other two materials. So the grey cast iron has thermally best compared to other materials. By these two analysis we can say that Titanium alloy has poor properties. For that it producing poor results compared to other two materials. Grey cast iron (GCI) and stainless steel (SS) are available with very cheap in price as compared to titanium alloy (TA) material. By these results titanium alloy is not suitable material for production of automobile braking components in terms of performance and cost. Finally we concluded that disc 1 model with stainless steel material has got better results in structural analysis and model with grey cast iron have obtained less temperatures. Disc 1 Model will give best outputs either with SS or GCI material. Hence the disc 1 model is suggestible to use in automobile applications.

\section{REFERENCES}

1. Mr.PravinN.Jawarikar, Dr.SubinN.Khan, Mr.BalajiD.Kshirsagar, "Structural Optimization, Thermal and Vibration Analysis of two wheeler disc brake rotor", (IOSR-JMCE), e-Vol. No.2,ISSN:08-1684,August 2016.

2. Boniardi.M, D’Errico.F, Tagliabue.C, Gotti.G, Perricone.G, "Failure analysis of motorcycle brake disc", Elsevier, April 2005 .

3. Nilesh K. Kharye, Dr.SharadS Chaudhari, "Investigation of Natural frequency and modal analysis of brake rotor using Fea and Ema”, International Journal of Innovative Research in Science, engineering and Technology, Vol 3, October 2014. 
4. Belhocine A,Ghazai N M, Abdullah O.I, "Structural and contact analysis of a 3-Dimensional Disc-Pad model with and without Thermal effects", Tribology in Industry, Vol.36,No. 4(2014) 406-418.

5. Madhumaheswara Reddy Y and Dr. UshaSriP, "Heat transfer analysis of automotive disc brakes",IJARSE, Vol.No.3,Issue No.9,September 2014.

6. Abu Bakar A.R, Ouyang $H$ and Cao Q, "Interface pressure distribution through structural modifications", SAE technical paper series, 2003-01-3332.

7. Nikam, H., Mishra, P. R. E. M., \& Bharambe, S. (2014). Design and Analysis of Brake Rotor with Parameter Optimization. International Journal of Automobile Engineering Research and Development (IJAuERD), 4(4), 21-30.

8. Manjunath T.V and Dr. SureshP.M, "Structural analysis of rotor disc of a disc brake", IJIRSET, Vol.2, Issue 12, December 2013.

9. Baron Saiz C, Ingrassia T,Nigrelli V, and Ricotta V', Thermal stress analysis of different full and ventilated disc brakes, 2015. 